\title{
A IMPORTÂNCIA DA QUALIDADE DE VIDA NO TRABALHO E DA MOTIVAÇÃO DOS COLABORADORES DE UMA ORGANIZAÇÃO
}

DOI: $10.22289 / 2446-922 X . V 3 N 2 A 3$

\author{
Geovani Batista Ferreira ${ }^{1}$ \\ Cátia Castro Dias
}

\section{RESUMO}

Nos casos extremos de insatisfação dos colaboradores com a organização, pode ocorrer o estresse e até mesmo surgirem sintomas físico-emocionais como a ansiedade e a depressão. São pontos relevantes se não evitados pois comprometem a eficiência dos funcionários e influencia até mesmo no surgimento de doenças psicossomáticas. Como consequência, podem tornar funcionários incapazes de alcançar seus desejos pessoais e suas metas profissionais dentro da empresa. O objetivo do estudo foi discorrer sobre a importância da QVT e a motivação dos colaboradores para a conquista dos objetivos e o sucesso das organizações. Este artigo tem como excelência mostrar a necessidade de uma gestão voltada para a QVT e sua influência sobre a motivação organizacional. A literatura investigada apontou que empresas que valorizam o ser humano e que investem na QVT e na motivação de seus funcionários, estes têm maior compromisso e responsabilidade, contribuindo ativamente para o sucesso organizacional. No entanto, o impacto na QV pode causar aos funcionários a insatisfação e ausência de motivação, resultando em baixa produtividade. Empresas que têm uma política voltada para a QV, que valorizam a dignidade do ser humano e o reconhece como competência fundamental, tornam-se mais competitivas e com maior possibilidade de se firmarem no mercado.

Palavras-chave: Qualidade de Vida; Motivação; Organização.

\section{ABSTRACT}

In extreme cases of employee dissatisfaction with the organization, stress may occur and even physical-emotional symptoms such as anxiety and depression may arise. They are relevant points if not avoided because they compromise the efficiency of the employees and influence even in the emergence of psychosomatic diseases. Consequently, they can make employees unable to achieve their personal desires and career goals within the company. The objective

\footnotetext{
${ }^{1}$ Endereço eletrônico de contato: geovanibf1@yahoo.com.br Recebido em 27/09/2017. Aprovado pelo conselho editorial para publicação em 11/10/2017.
}

Rev. Psicol Saúde e Debate. Dez., 2017:3(2):30-43. 
of the study was to discuss the importance of QLW and the motivation of the employees to achieve the goals and the success of the organizations. This article has as excellence to show the need for a management focused on the QWL and its influence on the organizational motivation. The investigated literature pointed out that companies that value human beings and that invest in QLW and the motivation of their employees have greater commitment and responsibility, contributing actively to organizational success. However, when the affected QL can provide employees with dissatisfaction and lack of motivation, resulting in low productivity. Companies that have a policy focused on $\mathrm{QL}$, which value the dignity of the human being and recognize it as a fundamental competence, become more competitive and more likely to establish themselves in the market.

Keywords: Quality of Life; Motivation; Organization.

\section{INTRODUÇÃO}

Com o advento do capitalismo e da globalização, houve uma grande expansão comercial e abertura das relações internacionais. Uma multiplicação que se estabeleceu entre os agentes econômicos situados nos mais diversos pontos do espaço (Chesnai, 1995).

Nessa crescente evolução da tecnologia e a constante busca por melhores resultados, o mundo vive hoje momentos de transição. Surge um novo conceito de mercado, onde a competitividade reflete uma necessidade de novas estratégias no ambiente de trabalho e no mercado mundial. Surge uma gestão com uma mentalidade preocupada com Qualidade de Vida e preservação da integridade física e emocional do trabalhador (Moretti \& Treichel, 2003).

Com o aumento da competitividade, são cada vez maiores as exigências de dedicação e esforços por parte dos empregados. Existem empresas que se preocupam em se assegurar de novos insights que deem suporte para que se mantenham em atividade plena (Santos, 2014).

O trabalhador tornou-se a peça-chave em uma organização. É desse trabalhador que a empresa depende para manter-se competitiva no mercado mundial. E neste sentido, para que os funcionários se sintam motivados e comprometidos, é necessário criar um ambiente positivo e acolhedor que torne a rotina agradável e menos sacrificante (Hilion, 2011).

Investimentos em tecnologia e marketing são cada vez mais importantes. Por outro lado, o ser humano é responsável por conduzir e produzir estes resultados (Carvalho et al., 2013).

A ausência de uma gestão voltada para a QVT, a presença de práticas de trabalho inadequadas e o não compromisso por parte da empresa geram um impacto negativo na 
saúde física e emocional dos funcionários prejudicando não somente a vida do trabalhador, bem como também o sucesso organizacional (Carvalho, 2016).

É importante flexibilizar as estruturas organizacionais, que sejam inovadoras e que mantenham seus funcionários motivados e com qualidade de vida, para enfrentarem o novo conceito de trabalho em que o homem não é mais visto como uma máquina, mas como competência básica, um ser participativo e dinâmico que promove o sucesso organizacional. (Souza, Campos Júnior, \& Magalhães, 2015).

O objetivo deste estudo foi discorrer sobre a importância da QVT e a Motivação dos colaboradores nas organizações para a conquista dos resultados e do sucesso almejado.

O método utilizado neste artigo foi o da pesquisa bibliográfica, de natureza descritiva e com abordagem qualitativa em artigos disponibilizados em bancos de dados da internet, em bases de dados como Scielo e Google acadêmico, através das seguintes palavras-chave: qualidade de vida, motivação, organização, no período de Fevereiro a Setembro de 2017 e em livros, possibilitando avaliações de produções atuais de diversos autores com conhecimento no assunto, dívida em: conceituar qualidade de vida no trabalho e processo motivacional; as teorias da motivação humana, a diferenciação e a motivação humana.

\section{QUALIDADE DE VIDA NO TRABALHO E PROCESSO MOTIVACIONAL}

A Qualidade de Vida no Trabalho (QVT) é um princípio primordial pessoal e organizacional em uma empresa. Para que este programa de QVT seja administrado e traga benefícios para colaboradores e empresa é necessário que haja um novo olhar por parte das lideranças no ambiente de trabalho. Considerando-se os aspectos biológicos, psicológicos e sociais, são fatores específicos a serem trabalhados que influenciam diretamente no clima organizacional, podendo gerar resultados positivos para a empresa (Libio, 2016)

O programa QVT é uma forma construtiva de pensar, algo com finalidade de facilitar e satisfazer as necessidades do trabalhador durante a execução de suas tarefas no espaço organizacional. É um conjunto de ações de uma empresa no sentido de implantar melhorias e inovações gerenciais, tecnológicas e estruturais no ambiente de trabalho. Parte do pressuposto de que a motivação é essencial para um maior comprometimento de seus funcionários, resguardando os objetivos da empresa e ajustando os interesses dos funcionários (Ribeiro\& Santana, 2015). 
A QVT representa o grau em que os membros da organização são capazes de satisfazer suas necessidades pessoais através do seu trabalho na organização (Santos, 2014; Chiavenato, 2010). A QVT tem duas posições diferenciadas: o bem-estar e a satisfação que representam o grau em que os funcionários são capazes de satisfazer suas necessidades através do trabalho e, por outro lado, a organização e seus interesses quanto ao atingimento de seus objetivos e metas (Carvalho, 2016; Chiavenato, 2009).

Para que exista QV nas organizações é necessário que as condições físicas, psicológicas e sociais sejam essenciais e estejam em constante melhoria para proporcionar um clima organizacional de maior satisfação para os colaboradores no ambiente de trabalho. Quando a gestão é voltada para a otimização dos recursos humanos e tem como meta gerar uma organização mais humanizada, tem como objetivos evitar a baixa motivação, que é uma consequência gerada pela ausência de QVT (Chiavenato, 2009; Ribeiro \& Santana2015).

Na perspectiva Humanista, a QVT preocupa-se em valorizar o ser humano como um todo. O homem como um ser que merece respeito, dotado de sentimentos, pretensões, sonhos, realizações, conhecimentos e necessidades. São ideias prioritárias que estão acima de qualquer ideia de exploração (Moretti \& Treichel, 2003; Amatuzzi, 1989).

A filosofia de QVT para Santos (2014), ocorre na cultura organizacional, sendo a priori os valores que levam em conta a importância do ser humano. QVT é um constructo que viabiliza o ajuste e o bem-estar do ser humano nos aspectos psicológico, da saúde e social. São aspectos relevantes para um maior desempenho dos colaboradores: satisfação com o trabalho executado, as promoções, o reconhecimento como profissional, o salário percebido, o relacionamento interpessoal, a capacitação, o ambiente de trabalho, a liberdade de atuar e tomar decisões e a possibilidade de atuar ativamente na organização. A motivação para o trabalho, a criatividade, a vontade de inovar ou aceitar mudanças e agregar valor na organização são aspectos de QVT que está ligada a motivação, responsável por promover mudanças nas atitudes pessoais e comportamentais dos funcionários, algo bastante relevante para a produtividade (Chiavenato, 2010; Ribeiro \& Santana, 2015).

O controle de QVT visa promover um clima organizacional mais estável, uma atmosfera psicológica positiva, ou seja, entender que este clima está ligado com a satisfação e com a motivação, que faz parte do processo de equilíbrio emocional dos funcionários. Esse clima organizacional faz menção à percepção que os funcionários têm sobre o ambiente de trabalho, o que cada colaborador sente em relação à empresa, podendo ser um ambiente positivo ou negativo (Chiavenato, 2010; Oliveira, Carvalho \& Rosa, 2012).

Organizações que olham por outro prisma, que investem em uma gestão que valoriza a Qualidade de Vida no Trabalho, na motivação e na satisfação dos funcionários, são mais

Rev. Psicol Saúde e Debate. Dez., 2017:3(2):30-43. 
eficazes e superam os desafios de mercado. Sem essa ideia de QV e motivação, as organizações enfrentariam uma série de dificuldades. Funcionários motivados e com QVT mantêm compromisso com a organização (Sousa, 2004).

A QVT tem a finalidade de manter o bem estar do trabalhador no espaço organizacional, evitando a insatisfação e os fatores estressantes advindos do trabalho e que podem comprometer a capacidade emocional e física do trabalhador. Desta forma, as consequências podem ser desde a diminuição da motivação ou mesmo algo significativo e sintomático como a depressão, ansiedade e as doenças psicossomáticas que trazem ao indivíduo situações desconfortáveis que podem prejudicar tanto a sua vida pessoal quanto profissional (Carvalho, 2016).

Para compreender a ressonância do conceito motivação é preciso analisar como é formado o ciclo motivacional; onde o mesmo é constituído por uma ocorrência de fenômenos, desde superar uma necessidade e sua satisfação até a retomada de seu estado inicial, o de equilíbrio. Quando existe uma necessidade cria-se uma tensão que estimula um impulso que gera um comportamento de realização da causa. O atingimento da satisfação produz a atenuação da tensão e volta ao estado inicial (Santana, Andrade\& Jesus, 2016).

A dinâmica motivacional é um processo sistêmico e cíclico. A $1^{\circ}$ fase do ciclo é a necessidade, a ideia, o foco e a carência interna da pessoa em busca de algo. $\mathrm{Na} 2^{\circ}$ fase $\mathrm{o}$ impulso gerado pela tensão aparece como a mudança de comportamento em querer satisfazer a necessidade e na realização desta. $\mathrm{Na} 3^{\circ}$ fase surge o incentivo do indivíduo, a perseverança para conseguir satisfazer suas necessidades e ao término, inicia-se a $4^{\circ}$ fase do ciclo, que fecha todo o processo com a realização do objetivo e dá-se início a um novo ciclo com novas necessidades e com novos impulsos (Santos, \& Silva, 2015).

A motivação é um sistema dinâmico e responsável que através de sua intensidade, direção e persistência dos esforços, incentiva a pessoa a conquistar uma determinada meta. Direção: foca o comportamento para alcançar algum objetivo. O objetivo pode ser organizacional ou individual (desejado pela pessoa). Intensidade: esforço que a pessoa aplica na direção definida, o objetivo desejado. Persistência: o tempo de persistência pelo objetivo (Santos \& Silva, 2015; Robbins, 2005).

A motivação representa a mola propulsora para o trabalho. Uma gestão organizacional que busca realizações pessoais visando os interesses das organizações cria funcionários motivados, que geram produtividade e têm mais envolvimento com a empresa (Silva \& Estender, 2015).

Motivação é um processo responsável que intensifica o esforço e a persistência do indivíduo, para que prossiga no alcance de seus objetivos (Ribas, 2011; Robbins, 2005).

Rev. Psicol Saúde e Debate. Dez., 2017:3(2):30-43. 
A motivação é uma pulsão interior de importância decisiva no desenvolvimento do ser humano. Algo ativo na vida do indivíduo, tanto nas decisões quanto nas necessidades. São razões subjacentes - ocultas - ao comportamento humano (Raquel, Borsa \& Santos, 2012).

Motivação é uma força motriz que incentiva as pessoas a agir na busca de algum objetivo. Parte do pressuposto de que cada um de nós dispõe de recursos próprios e tem sempre origem numa necessidade. A motivação não é determinada pela ação de outras pessoas como supunham, mas sim através do próprio mundo (Gil, 2017; Donato, Gonçalves. \& Sanches, 2011).

Esta ação dinâmica envolve a personalidade, ou seja, atividades relacionadas ao comportamento, à inteligência, à faculdade de conhecer, compreender, raciocinar, pensar, interpretar e elaborar. As necessidades estão ligadas ao desejo, às emoções, aos instintos, às experiências vividas e a todos os dados incorporados ao psiquismo incorrido durante a vida. Esta força interna tensional é a responsável e capaz de mudar o comportamento e seguir adiante nas situações da vida, na direção da realização do motivo (Costamtino, 2010).

Quando a necessidade é reprimida, o impulso de realização e desejo não é liberado, ocasionando frustação, o organismo procura um meio de liberar esta tensão através do meio psicológico e fisiológico. Esta carga tensional causa um desequilíbrio e surge reações adversas bem como: tensão emocional, tensão nervosa, estresse, insônia, irritabilidade, pessimismo, resistência na vida, angustia, etc, alterando o metabolismo mente-corpo. Uma necessidade não satisfeita afeta diretamente o comportamento humano, com fator desmotivador. O que envolve a necessidade de sentir-se valorizado e a auto realização, é tornar-se o melhor que você pode ser ou é capaz de ser (Paula, 2011).

\section{TEORIAS DA MOTIVAÇÃO HUMANA}

As Teorias Motivacionais estudam quais os fatores agem sobre o indivíduo para alterar o seu comportamento. No que diz a respeito à interface da Psicologia e Administração, as teorias fundamentam a construção de programas de motivação, satisfação, produtividade e trabalho em equipe (Carvalho, 2014).

A motivação por objetivo, extrínseca, está relacionada ao ambiente, às situações e aos estímulos externos. São fatores motivacionais que através de benefícios proporcionam a satisfação em efetuar tarefas. Este tipo de motivação sempre será útil no papel da liderança, na mudança de comportamento de seus colaboradores para que se mantenham engajados

Rev. Psicol Saúde e Debate. Dez., 2017:3(2):30-43. 
para alcançarem resultados de interesses comuns. A satisfação pessoal é apenas uma consequência de uma ação. Etapas: Despertar a iniciativa - Direcionar para o objetivo - Fixar metas para o objetivo - Recompensar por ter alcançado o objetivo (Robbins, 2005; Ribas, 2011).

A motivação por necessidade própria, intrínseca, também conhecida por motivação interna, está relacionada com a força interior, da satisfação, do desafio e do desejo. O prazer advém da tarefa em si, simplesmente da satisfação de estar fazendo algo de interesse pessoal, focado até o final da realização do objetivo. São interesses individuais e não de um objetivo proposto que faça mudar o comportamento para incentivá-lo. Pode ser alterado somente pela decisão da pessoa. Quando o indivíduo realiza uma necessidade própria sempre surgirá outra em seu lugar. Sendo assim uma motivação é cíclica e de ordem psicológica (Dialamícua, 2014).

Elaborada por Abraham Maslow, (1908-1970), é uma das teorias mais importantes e conhecidas, pois as necessidades obedecem a uma hierarquia. Esta hierarquia determina as condições necessárias para que o ser humano atinja a sua auto realização. Assim é apresentada como a relação hierárquica de cinco necessidades, chamada de pirâmide de Maslow. Fundamenta-se na existência de necessidades a serem satisfeitas, a fim de que alcancemos nosso bem-estar. Através de uma pirâmide, Maslow descreve a Teoria da Hierarquia das Necessidades, conforme figura 1 e mostra quando uma necessidade é alcançada (Carvalho, 2014).

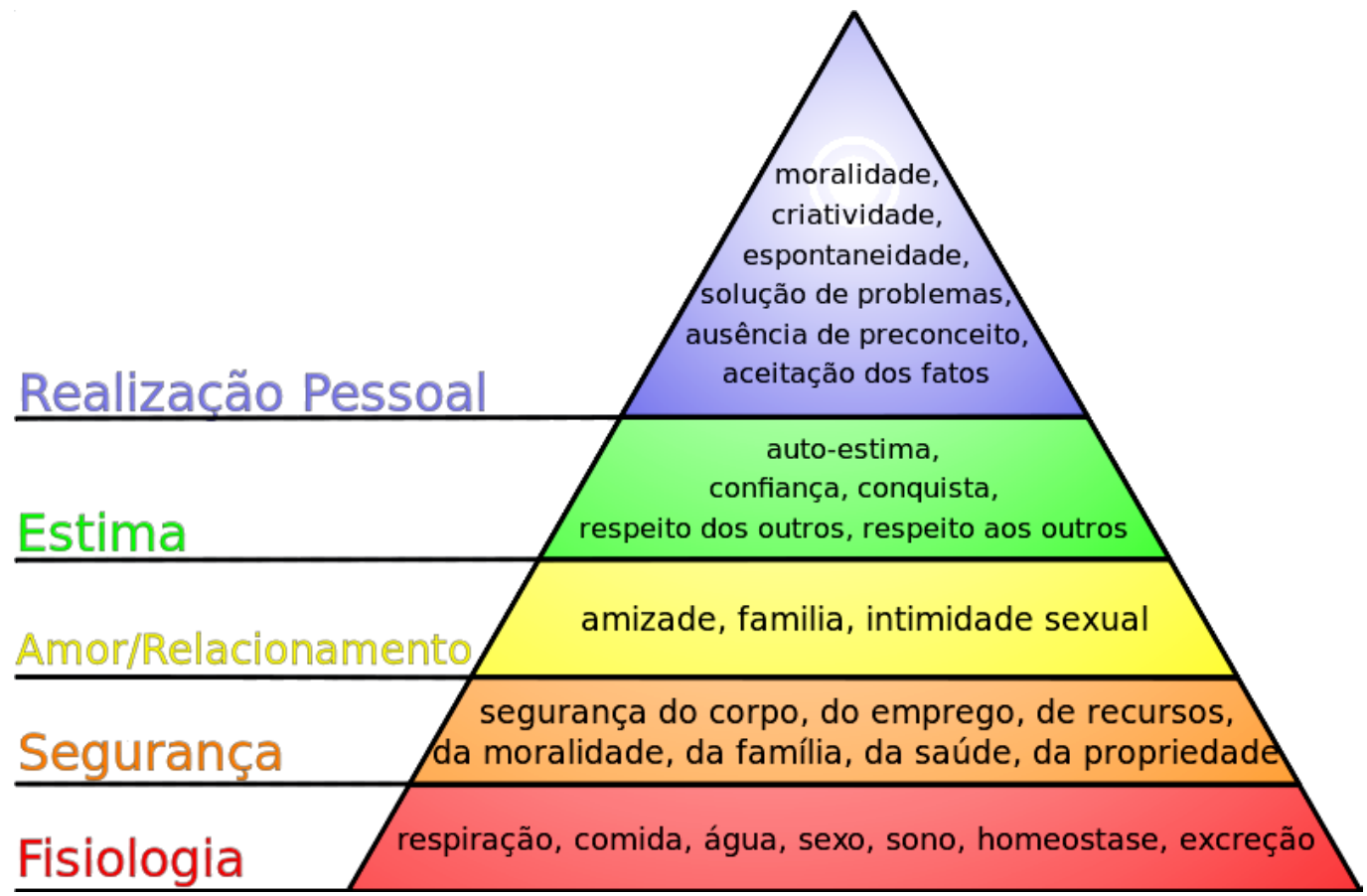

Figura 1. Pirâmide de necessidades de Maslow. Fonte: (Carvalho, 2014)

Rev. Psicol Saúde e Debate. Dez., 2017:3(2):30-43. 
Neste contexto da teoria das Necessidades Humanas, para alcançar a motivação do nível mais alto da pirâmide que é a necessidade de "auto realização", a priori é necessário satisfazer as necessidades mais baixas: autoestima, amor/relacionamento, segurança, fisiologia, para depois se apoderar da necessidade mais alta. Assim, quando uma necessidade é realmente satisfeita, aproxima-se da necessidade mais elevada, tornando-se a próxima necessidade a ser realizada (Chiavenato, 2014; Santos \& Silva, 2015).

A teoria dos dois fatores de Frederick Herzberg, (1923-2000), explica como o ambiente e o próprio trabalho se integram, para manter funcionários motivados e com maior satisfação. Esta Teoria dos dois fatores de Herzberg não tem como prioridade satisfazer as necessidades dos indivíduos como a teoria de Maslow. A teoria está mais ligada às recompensas e aos resultados de desempenho dos colaboradores (Chiavenato, 2015; Libio, 2016).

Trata-se de uma teoria alicerçada no ambiente externo e no trabalho do indivíduo, e divide-se em dois fatores:

Fatores Higiênicos de manutenção: São extrínsecos. É no ambiente de trabalho que se desenvolve este fator, e pontuam fatores deficientes que causam insatisfação no trabalho. Também se percebe se os funcionários estão motivados e comprometidos com aquilo que fazem. Entre os fatores de insatisfação, higiênicos, destacam-se o salário, as condições de trabalho, as políticas da empresa, a comunicação entre gestão e funcionários, etc. Todos eles podem alterar o contexto em que o trabalho é executado. Os fatores higiênicos ou de manutenção apenas evitam a insatisfação, mas não a provoca. Estes fatores são responsáveis por tornar o ambiente mais saudável (Chiavenato, 2014; Santos \& Silva, 2015).

Fatores Motivacionais Intrínsecos. Ao contrário do descrito nos fatores higiênicos, estes são fatores motivacionais que envolvem sentimentos de realização pessoal e relacionam-se com o trabalho em si, enquanto o desempenho do trabalhador, o seu reconhecimento, a responsabilidade, a realização e o crescimento estão por ele assegurados, mediante a realização das tarefas. Estes fatores motivacionais concentram a sua maior parte no trabalho e sua presença leva a altos níveis de motivação e de satisfação no trabalho (Sousa, 2004).

Os fatores higiênicos dizem respeito a como as pessoas são tratadas pela organização e os fatores motivacionais estão ligados ao uso que a organização faz da energia motivacional de cada um. São independentes e não vinculam entre si, conforme observado na figura 2 (Chiavenato, 2014; Santos \& Silva, 2015; Sousa, 2004).

Rev. Psicol Saúde e Debate. Dez., 2017:3(2):30-43. 


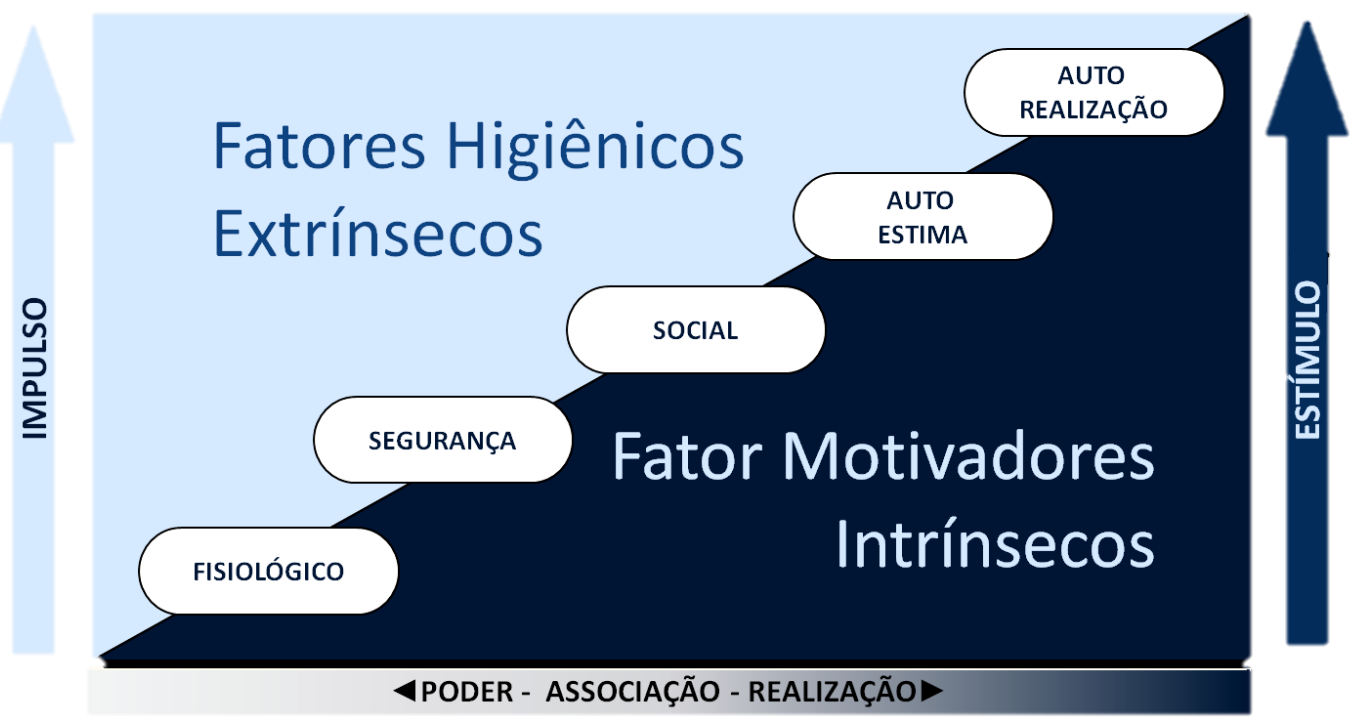

Figura 2. Fatores Higiênicos e Fatores Motivacionais. Fonte: (Ribas, 2011).

\section{DIFERENÇAS ENTRE MASLOW E HERZBERG: a motivação}

\section{organizacional}

De certa forma, pode-se conferir alguma similaridade entre as necessidades fisiológicas, de segurança e sociais de Maslow, com os fatores higiênicos de manutenção de Herzberg. Encontra-se ainda similaridade nos fatores motivacionais de Herzberg com as necessidades de autoestima e auto realização de Maslow (Hilion, 2011). A figura 3 permite observar o comparativo.

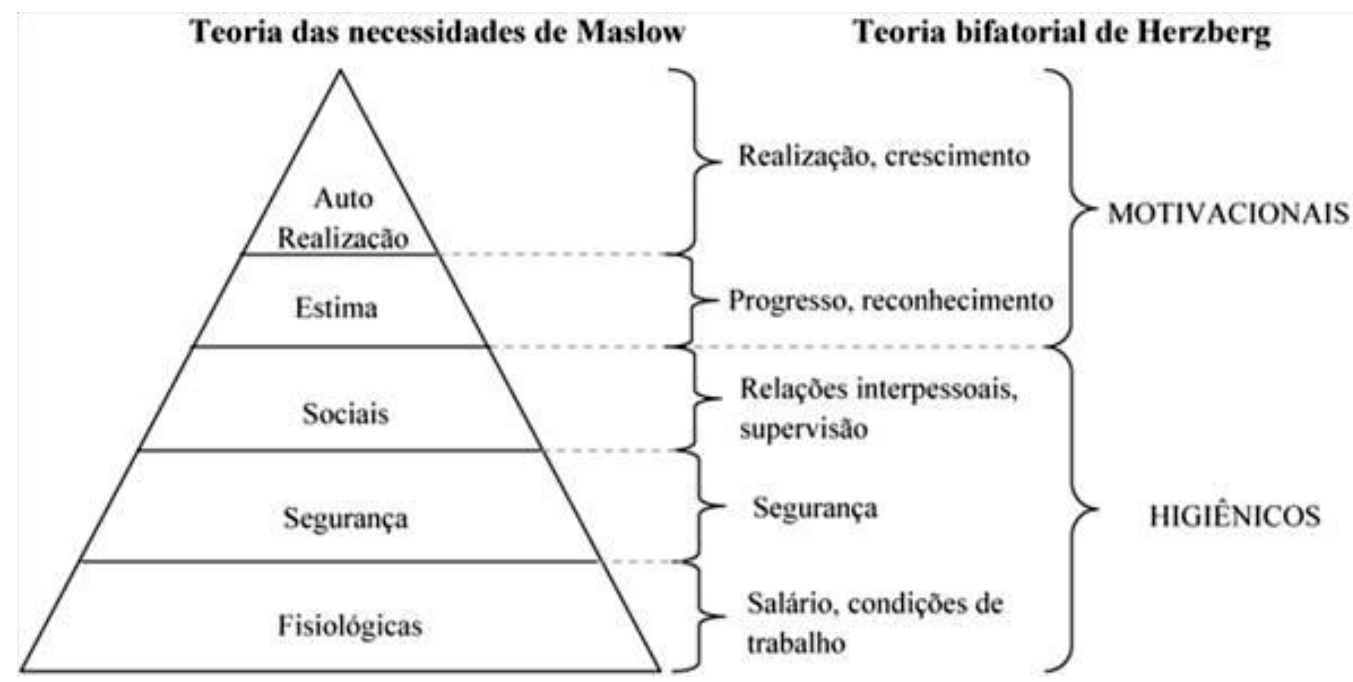

Figura 3. Comparativo da Teoria de Maslow e Herzberg. Fonte: (Chiavenato, 2015).

Rev. Psicol Saúde e Debate. Dez., 2017:3(2):30-43. 
Na perspectiva de Maslow, o ser humano tem necessidades especificas a serem cumpridas, dispostas numa ordem hierárquica. Primeiro tem que passar pelo nível mais baixo da pirâmide, só assim poderá realizar as necessidades do topo. Na teoria das necessidades, o comportamento do indivíduo está motivado pelas necessidades de auto realização e estima (Chiavenato, 2015; Libio, 2016).

O que estabelece a diferença entre as teorias motivacionais de Maslow e Herzberg é que Maslow formulou sua teoria dentro das perspectivas das necessidades humanas. Herzberg por sua vez considerou o ambiente externo e o trabalho do indivíduo, metas e recompensas (Chiavenato, 2014; Santana, Andrade \& Jesus, 2016).

As teorias motivacionais de Maslow e Herzberg e outros teóricos nos permitem a possibilidade de um entendimento diferencial a respeito do processo motivacional nas organizações. Permitem ainda que gestores criem estratégias para um clima organizacional eficaz (Chiavenato, 2015; Libio, 2016).

É através da competência humana que as organizações sobrevivem. A motivação através de suas estratégias motivacionais tem papel fundamental na mudança do comportamento de seus funcionários (Santos, 2014).

Quando existe um bom relacionamento entre empresa e colaboradores, um clima organizacional favorável é muito importante para a motivação do indivíduo dentro e fora da organização, pois pessoas satisfeitas trabalham e vivem satisfeitas. Esta sintonia proporciona uma interação de ambos, uma reciprocidade que estimula a geração de novas ideias que possam inovar o ambiente de trabalho (Robbins, 2005; Gonzáles et al., 2007).

É de fundamental importância que os fatores motivacionais sejam contínuos para que os colaboradores se sintam motivados para desempenhar seu papel profissional. Alguns exemplos de fatores motivacionais nas organizações: realização profissional, reconhecimento, promoção, crescimento, salário, ótimas condições de trabalho, estabilidade, capacitação, segurança no trabalho, entre outros (Freitas, 2015).

Quando o funcionário se sente parte da organização, sabe que seu esforço empenhado é reconhecido e recompensado. A satisfação no trabalho é um dos fatores motivacionais capazes de mudar o comportamento do indivíduo em benefício da organização (Silva, 2011).

Se a satisfação estiver abaixo dos padrões ideais, isso pode gerar consequências negativas para a organização, como a baixa produtividade e até mesmo a falta de motivação. A satisfação está relacionada a como os funcionários se sentem no ambiente de trabalho. Diz respeito a como eles se vêem dentro da organização, de seus relacionamentos interpessoais com a gestão e colegas e implicam também as condições de trabalho e renumeração 
condizente com as atividades que exercem. Isso diz respeito a qual nível de influência que a empresa exerce sobre seus funcionários (Robbins, 2005; Silva, 2011).

Numa rotina de trabalho que causa estresse no decorrer dos dias, e que exerce uma influência de insatisfação e de mudança de comportamento não condizente com as expectativas, o funcionário tende a não manter compromisso com empresa, que por sua vez não corresponde às exigências de mercado. Esta insatisfação está relacionada com a maneira que cada indivíduo se percebe dentro do clima organizacional, ou seja, se o clima está favorável ou se está causando insatisfação no ambiente do trabalho. Isso pode ser até mesmo uma desmotivação coletiva organizacional (Tavares, 2002).

A desmotivação organizacional pode ser decorrente de várias situações: salário insatisfatório, local inadequado de trabalho, falta de reconhecimento profissional, organizações descomprometidas, ausência de promoções, demanda de trabalho maior que a estipulada, gestores autoritários, comunicação ineficiente com os funcionários, instabilidade, insegurança, dentre outras. São aspectos decorrentes e que têm como consequências: o absenteísmo, a baixa produtividade, a falta de comprometimento com a empresa, a alta rotatividade, etc. São fatores que estão estritamente ligados à insatisfação no trabalho. Estes fatores geram cansaço físico e mental do profissional, ocasionando desgaste emocional e desmotivação na realização de tarefas e na busca dos interesses da empresa (Robbins, 2005; Fernandes, 2009).

Uma empresa que se preocupa com a QVT, com a satisfação de seus funcionários e tem um clima organizacional motivador, sempre tende a elaborar planos de ações para suprir as necessidades de seus funcionários, para uma melhor eficácia organizacional. A satisfação e a motivação não se resume somente no salário auferido, mas também pelo respeito e reconhecimento de sua importância dentro da organização (Oliveira \& Medeiros, 2016).

\section{CONSIDERAÇÕES FINAIS}

Este estudo traz notório conteúdo acerca da importância da Qualidade de Vida no Trabalho e seus aspectos motivacionais.

Empresa com gestão inovadora, que investe em Qualidade de Vida, é uma organização humanizada que valoriza o capital humano. Organização que possui um clima organizacional que promove o bem-estar psicológico, o bem estar físico, a integridade moral, e que incentiva e capacita seus funcionários, torna-se atrativa para o trabalhador e garante

Rev. Psicol Saúde e Debate. Dez., 2017:3(2):30-43. 
um desempenho eficaz no mercado. No entanto, não há como se referir à QVT sem mencionar a motivação, a satisfação e as necessidades dos funcionários. São aspectos interligados, e não há como motivar um funcionário sem haver QVT. Preconizar QVT é incentivar a motivação pessoal e profissional dos funcionários de uma empresa.

A prioridade do programa QVT é identificar os pontos que prejudicam e interferem na satisfação no ambiente de trabalho. Assim, a QVT é um programa que abrange tanto as necessidades e expectativas pessoais como fatores situacionais ligados à tecnologia, à condição de trabalho, plano de carreira, cargo e salários, sistema de recompensas, implantação de benefícios, dentre outras. Mas não é possível implantar programas de qualidade, sem que as pessoas estejam motivadas e engajadas no trabalho. São circunstâncias nas quais as pessoas se sentem realmente motivadas, a projeção da autoestima elevada faz da situação do trabalho um caminho para se chegar a níveis mais altos de satisfação e realização pessoal. Assim a QVT deve buscar dentre outros conceitos, a valorização do ser humano e consequentemente a melhoria da autoimagem de cada indivíduo.

\section{REFERÊNCIAS}

Amatuzzi, M. M. (1989). O significado da psicologia humanista, posicionamentos filosóficos implícitos. Arquivo Brasileiro de Psicologia, 41(4),88-95.

Carvalho, R. J. (2014). Psicologia Organizacional e Teorias Motivacionais. Ágora, 10(19),1014.

Carvalho, M. L. (2016). Qualidade de vida no trabalho versus Condições Psicossomáticas advindas do mercado de Trabalho. Revista Eletrônica de Graduação, 9(1),67-84.

Carvalho, J. F. et al.. (2013). Qualidade de vida no trabalho e fatores motivacionais dos colaboradores nas organizações. Educação em Foco, 9(7), 21-31.

Costamtino, T. C. (2010). A Inteligência Emocional no Ambiente Organizacional. Monografia de Conclusão de Curso em Psicologia, Universidade do Extremo Sul Catarinense, Criciúma, SC.

Chesnai, F. (1995). A globalização e o curso do capitalismo de fim-de-século. Economia e Sociedade, 5(sn), 1-30.

Chiavenato I. (2015). Recursos Humanos: o capital humano nas organizações, 10 ed, São Paulo: Campus.

Chiavenato I. (2014). Introdução a Teoria Geral da Administração, 4 ed, São Paulo: Manole.

Rev. Psicol Saúde e Debate. Dez., 2017:3(2):30-43. 
Chiavenato I. (2014). Gestão de Pessoas: o Novo Papel dos Recursos Humanos nas Organizações, 4 ed, São Paulo: Manole.

Chiavenato I. (2009). Gestão de Pessoas, 3 ed, São Paulo: Campus.

Dialamícua, M. O. (2014). A influência da motivação intrínseca e das características da função no desempenho profissional dos trabalhadores da indústria hoteleira. Dissertação de Mestrado em Gestão de Recursos Humanos e Análise Organizacional, Faculdade de Ciências da Economia e da Empresa, Universidade Lusíada de Lisboa, Lisboa, Portugal.

Donato, C. J., Gonçalves, J. A. T. \& Sanches, M. A. R. (2011). A Liderança como Ferramenta de Motivação e Crescimento da Equipe de Vendas. Encontro de Iniciação Científica, 7(7),119.

Fernandes, P. R. S. (2009). Causas de Desmotivação no Trabalho em Uma Empresa Pública Federal. Monografia de Pós-Graduação em Administração, Faculdade de Economia e Administração, Contabilidade e Ciência da Informação e Documentação, Universidade de Brasília, Brasília, DF.

Freitas, K. C. C. (2015). O Desafio em Manter Colaboradores Motivados. Monografia de Conclusão de Curso em Administração, Instituto Municipal de Ensino Superior de Assis, Assis, SP.

Gil A. C. (2017). Gestão de Pessoas Enfoque nos Papéis Profissionais, 2ed, São Paulo: Atlas. Gonzáles, C. et al.. (2007). Estudo sobre Técnicas e Fatores Motivacionais nas Empresas. Conhecimento Interativo, 3(1),02-11.

Hilion, C. R. B. C. (2011). A Influência da Motivação no Trabalho sobre a Percepção do Risco. Dissertação de Mestrado em Segurança e Higiene no Trabalho, Escola Superior de Ciências Empresariais, Instituto Politécnico de Setúbal, Setúbal, Portugal.

Libio, A. S. (2016). Motivação Organizacional: Um estudo de caso em indústria de bebidas de Porto Alegre. Artigo de Conclusão de Curso em Administração, Faculdade Luterana São Marcos, Alvorada, RS.

Moretti, S. \& Treichel, A. (2003). Qualidade de vida no Trabalho x Autorealização Humana. Revista Leonardo Pos, 3(sn), 1-14.

Nascimento, M. S. S. \& Andrade, É. F. P. (2016). Qualidade de vida no trabalho e a motivação organizacional. Organizações e Sociedade, 5(4),38-51.

Oliveira, D., Carvalho, R. J. \& Rosa, A. C. M. (2012). Clima Organizacional: Fator de Satisfação no Trabalho e Resultados Eficazes na Organização. Simpósio de Excelência em Gestão Tecnologia, Rio de Janeiro, RJ.

Oliveira, G. S. \& Medeiros, L. (2016). Qualidade de vida no Trabalho: fatores que influenciam as organizações. Revista Campo do Saber, 2(2), 69-82.

Paula, G. T. L. (2011). A Influência do Clima Organizacional no Desempenho das Equipes no Jogo de Empresas. Revista LAGOS, 1(2),32-44. 
Pereira, J. M. \& Vidal, M. A influência do clima organizacional no desempenho das pessoas: um estudo de caso no fórum da comarca de Bezerros. Revista Eletrônica de Ciências, 4(1),117.

Raquel, L., Borsa, D. \& Santos, J. C. (2012). A Motivação de Funcionários nas Organizações. Revista de Ciências Sociais do Norte de Mato Grosso, 1(1), 1-9.

Ribas, R. (2011). A Motivação Empreendedora e as Teorias Clássicas da Motivação. Caderno de Administração, 5(1),1-19.

Ribeiro, L. A. \& Santana, L. C. (2015). Qualidade de vida no trabalho: fator decisivo para o sucesso organizacional. Revista de Iniciação Científica, 2(2),75-96.

Robbins S. P. (2005). Comportamento Organizacional, 11 ed. São Paulo: Pearson Prentice Hall.

Santos, J. A. (2014). Qualidade de Vida no Trabalho. Anais do X Congresso Nacional de Excelência em Gestão. Rio de Janeiro, RJ.

Santana, P. B. O., Andrade, D. C. R. \& Jesus, J. A. S. (2016). Terceirização na Administração Pública: Análise da Motivação dos Colaboradores Terceirizados no Serviço Público. Revista Multidisciplinar e de Psicologia, 10(30-supl2), 38-84.

Santos, J. C. \& Silva, E. R. R. (2015). A importância da motivação para o crescimento organizacional: um estudo de caso que foi realizado no grupo dm material de construção filial de Marabá/PA. Cadernos da Escola de Negócios, 1(13):200-25.

Silva, R. A. \& Estender, A. C. (2015). A Influência da Motivação no Local de Trabalho. Revista de Administração da UNISAL, 5(8),83-102.

Silva, S. S. M. (2011). Satisfação no Trabalho: um estudo de caso baseado nas teorias de Maslow e Herzberg. Monografia de Conclusão Curso de Especialização em Gestão de Pessoas, Universidade Federal do Paraná, Curitiba, PR.

Souza, T. A., Campos Júnior, D. J. \& Magalhães, S. R. (2015). A importância do Clima Organizacional. Revista da Universidade Vale do Rio Verde, 13(1),315-29.

Sousa, E. F. M. (2004). Motivação para Melhor Desempenho. Monografia de Curso de Pósgraduação em Administração Judiciária, MBA da Fundação Getúlio Vargas, Rio de Janeiro, RJ.

Tavares, F. P. (2002). Motivação e Desmotivação sob o Enfoque Organizacional. Revista Hispeci \& Lema, 6(sn),21-26.

Vieria et al.. (2011). Motivação na Administração Pública: considerações teóricas sobre uma aplicação dos pressupostos das teorias motivacionais na esfera pública. Revista ADMpg Gestão Estratégica, 4(1),1-18 